\title{
Daphmanidin A, a Novel Hexacyclic Alkaloid from Daphniphyllum teijsmanii
}

\author{
Jun'ichi Kobayashi, * Satoshi Ueno, and Hiroshi Morita
}

Graduate School of Pharmaceutical Sciences, Hokkaido University, Sapporo 060-0812, Japan

\section{Supporting Information}

Figure S1. $\quad{ }^{1} \mathrm{H}$ NMR spectrum of daphmanidin $\mathrm{A}(\mathbf{1})$ in $\mathrm{CD}_{3} \mathrm{OD}$.

Figure S2. $\quad{ }^{13} \mathrm{C}$ NMR spectrum of daphmanidin $\mathrm{A}(\mathbf{1})$ in $\mathrm{CD}_{3} \mathrm{OD}$.

Figure S3. $\quad{ }^{1} \mathrm{H}-{ }^{1} \mathrm{H}$ COSY spectrum of daphmanidin $\mathrm{A}(\mathbf{1})$ in $\mathrm{CD}_{3} \mathrm{OD}$.

Figure S4. NOESY spectrum of daphmanidin $\mathrm{A}(\mathbf{1})$ in $\mathrm{CD}_{3} \mathrm{OD}$.

Figure S5. HOHAHA spectrum of daphmanidin $\mathrm{A}(\mathbf{1})$ in $\mathrm{CD}_{3} \mathrm{OD}$.

Figure S6. HMQC spectrum of daphmanidin $\mathrm{A}(\mathbf{1})$ in $\mathrm{CD}_{3} \mathrm{OD}$.

Figure S7. HMBC spectrum of daphmanidin $\mathrm{A}(\mathbf{1})$ in $\mathrm{CD}_{3} \mathrm{OD}$.

Figure S8. $\quad{ }^{1} \mathrm{H}$ NMR spectrum of daphmanidin $\mathrm{A}(\mathbf{1})$ free base in $\mathrm{CD}_{3} \mathrm{OD}$.

Figure S9. $\quad{ }^{13} \mathrm{C}$ NMR spectrum of daphmanidin $\mathrm{A}(\mathbf{1})$ free base in $\mathrm{CD}_{3} \mathrm{OD}$.

Figure S10. $\quad{ }^{1} \mathrm{H}$ NMR spectrum of daphmanidin $\mathrm{B}(\mathbf{2})$ in $\mathrm{CD}_{3} \mathrm{OD}$.

Figure $\mathrm{S} 11 . \quad{ }^{13} \mathrm{C}$ NMR spectrum of daphmanidin $\mathrm{B}(\mathbf{2})$ in $\mathrm{CD}_{3} \mathrm{OD}$. 


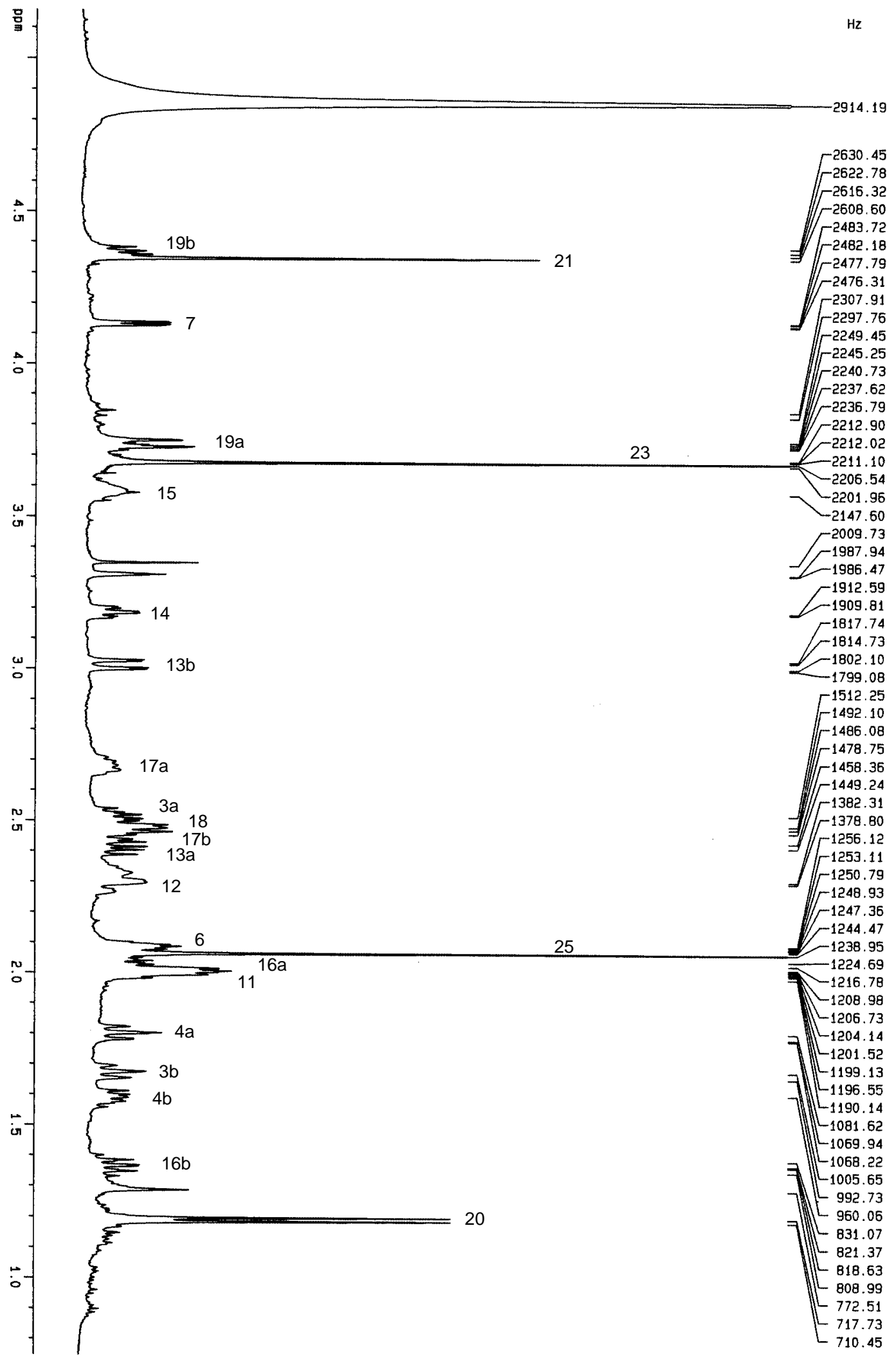

Figure S1. ${ }^{1} \mathrm{H}$ NMR spectrum of daphmanidin $\mathrm{A}(\mathbf{1})$ in $\mathrm{CD}_{3} \mathrm{OD}$. 


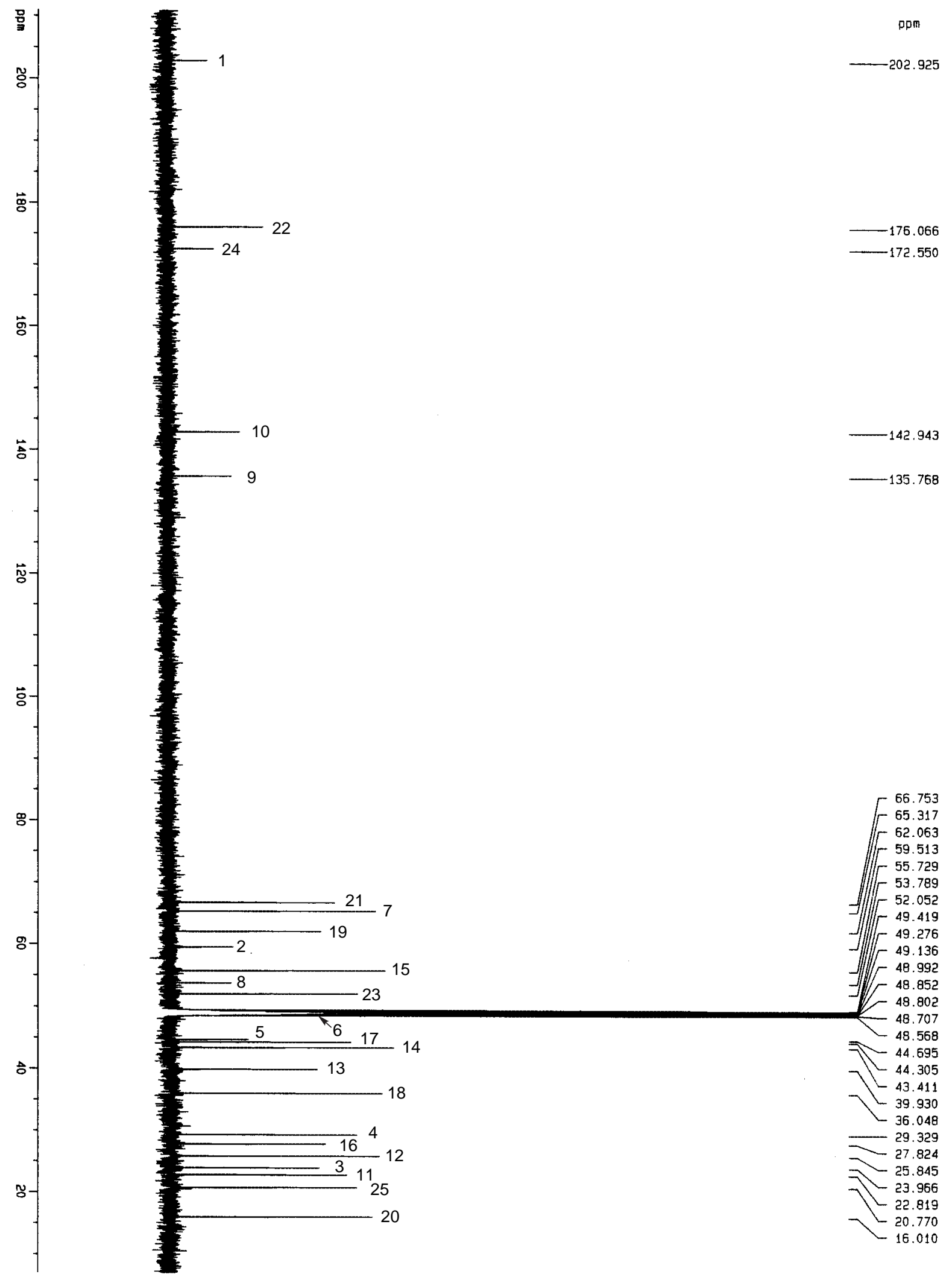

Figure S2. ${ }^{13} \mathrm{C}$ NMR spectrum of daphmanidin $\mathrm{A}(\mathbf{1})$ in $\mathrm{CD}_{3} \mathrm{OD}$. 


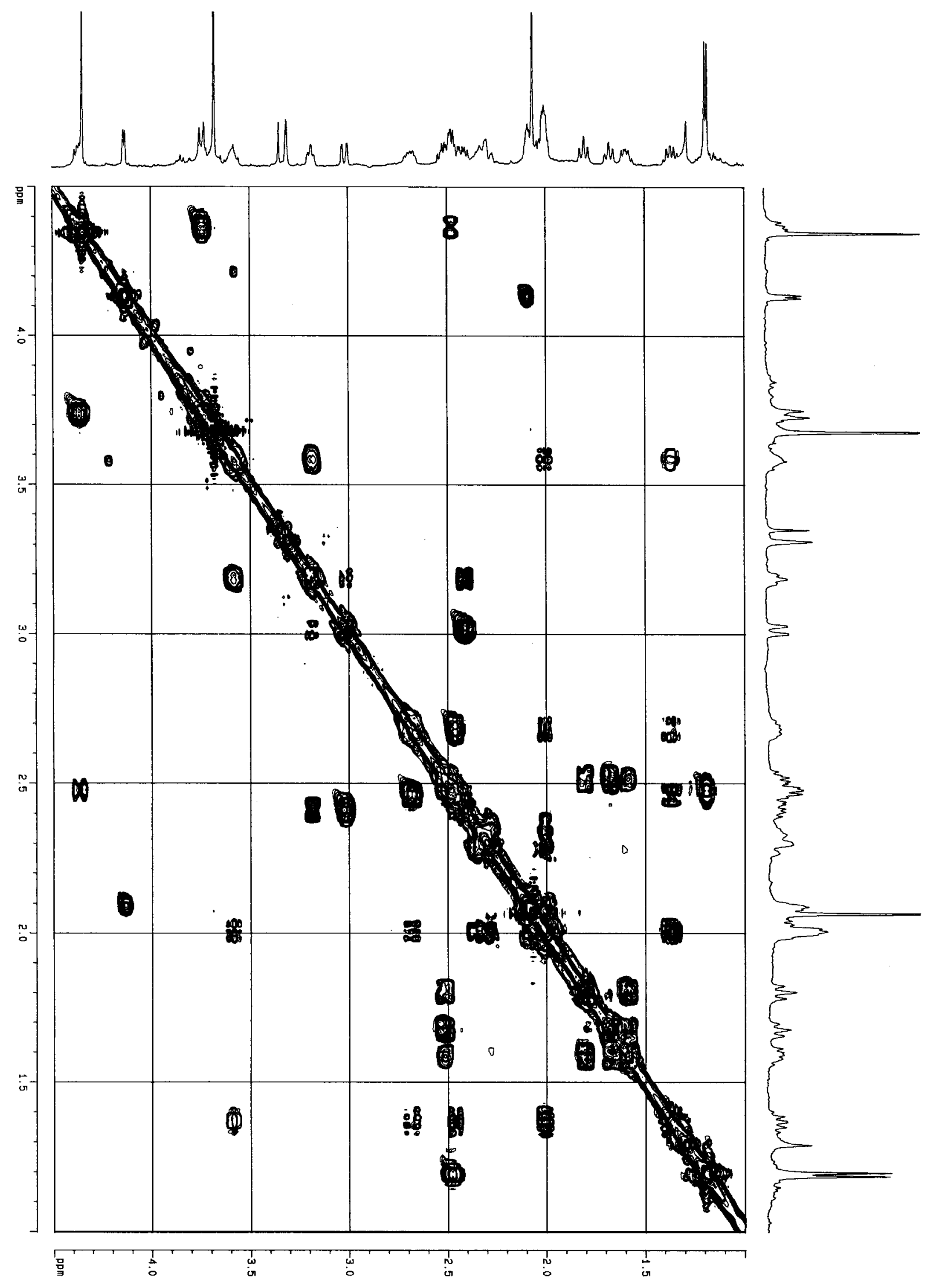

Figure S3. ${ }^{1} \mathrm{H}-{ }^{1} \mathrm{H}$ COSY spectrum of daphmanidin $\mathrm{A}(\mathbf{1})$ in $\mathrm{CD}_{3} \mathrm{OD}$. 


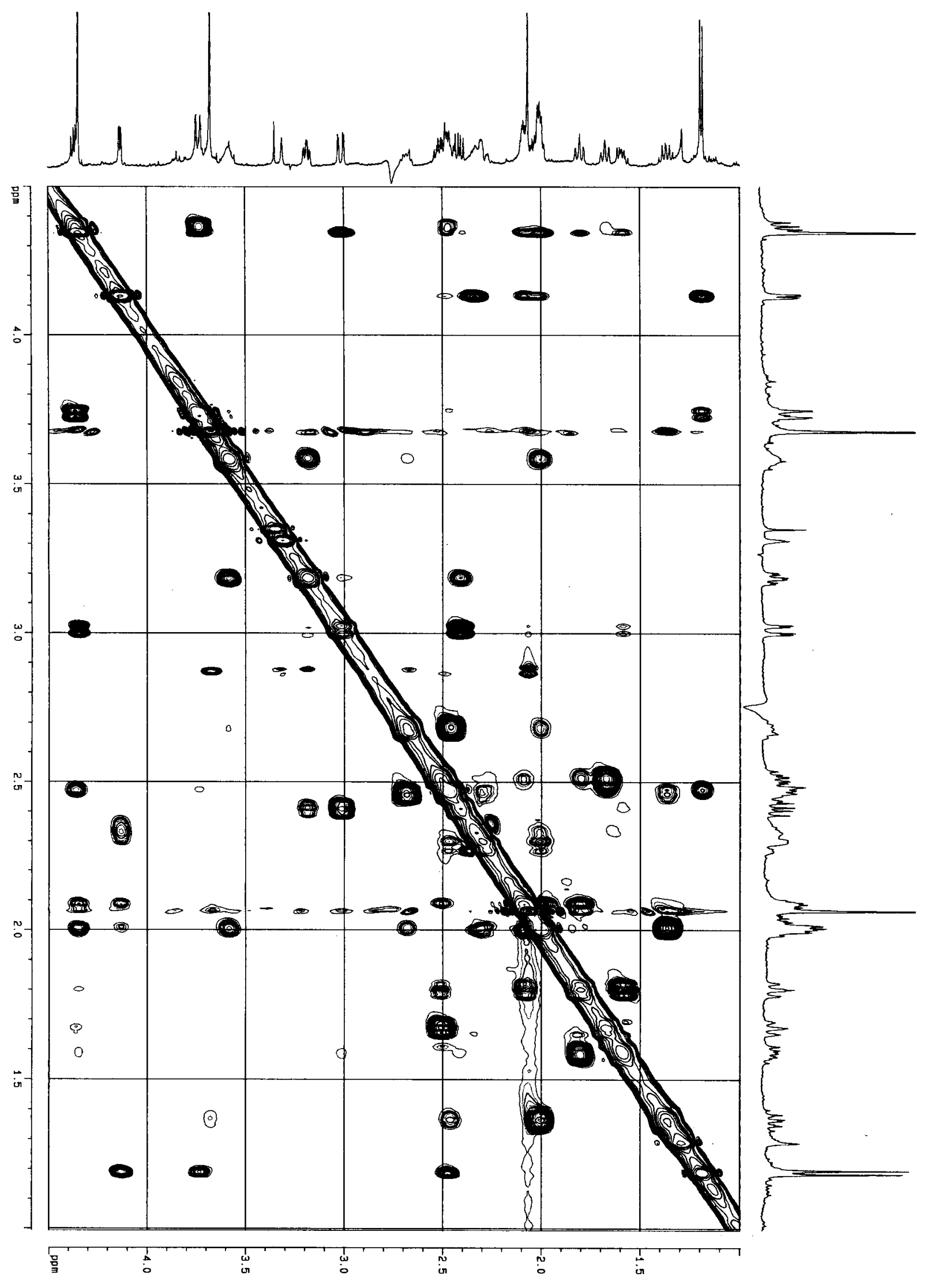

Figure S4. NOESY spectrum of daphmanidin A (1) in $\mathrm{CD}_{3} \mathrm{OD}$. 


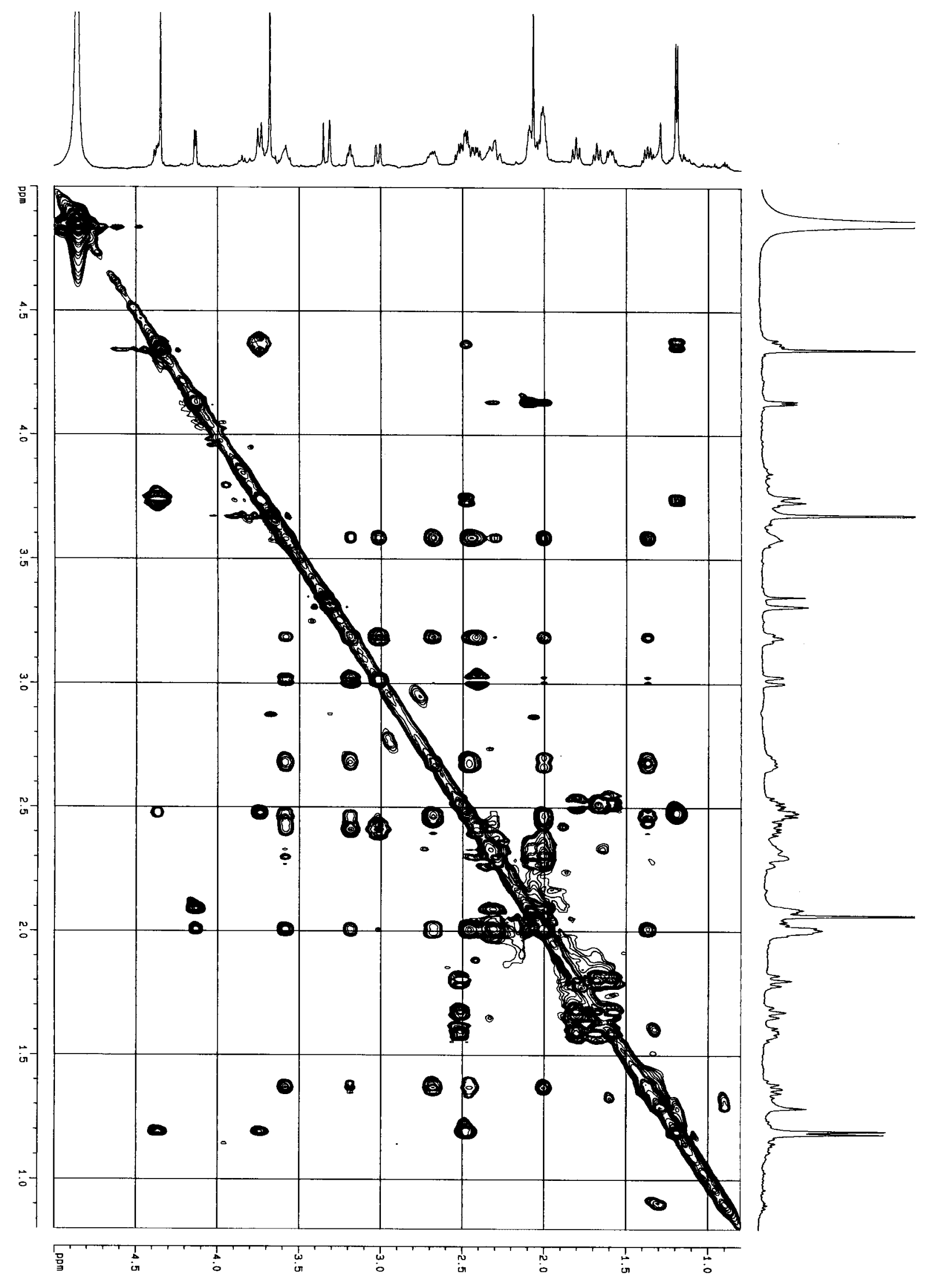

Figure S5. HOHAHA spectrum of daphmanidin $\mathrm{A}(\mathbf{1})$ in $\mathrm{CD}_{3} \mathrm{OD}$. 


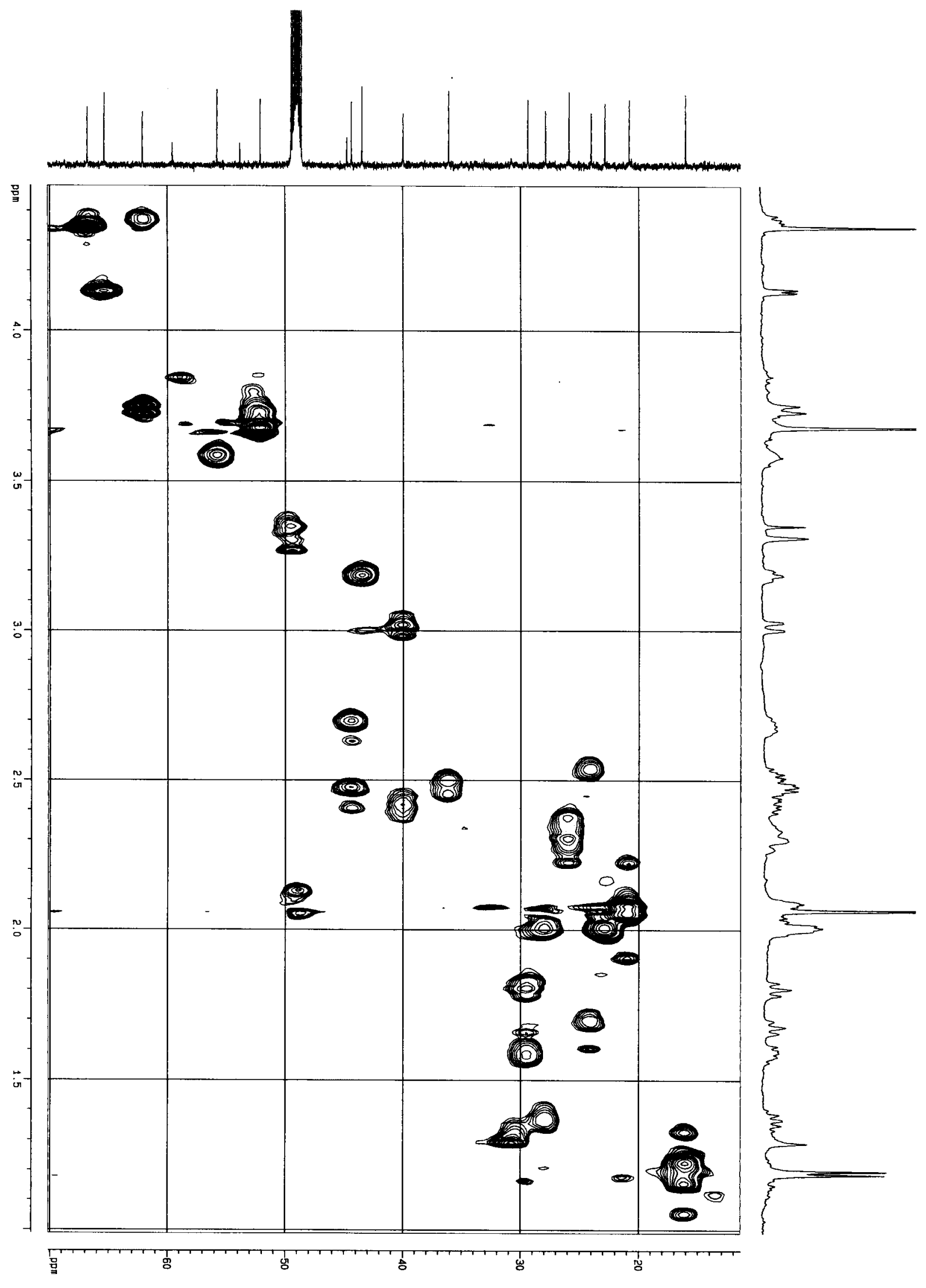

Figure S6. HMQC spectrum of daphmanidin $\mathrm{A}(\mathbf{1})$ in $\mathrm{CD}_{3} \mathrm{OD}$. 


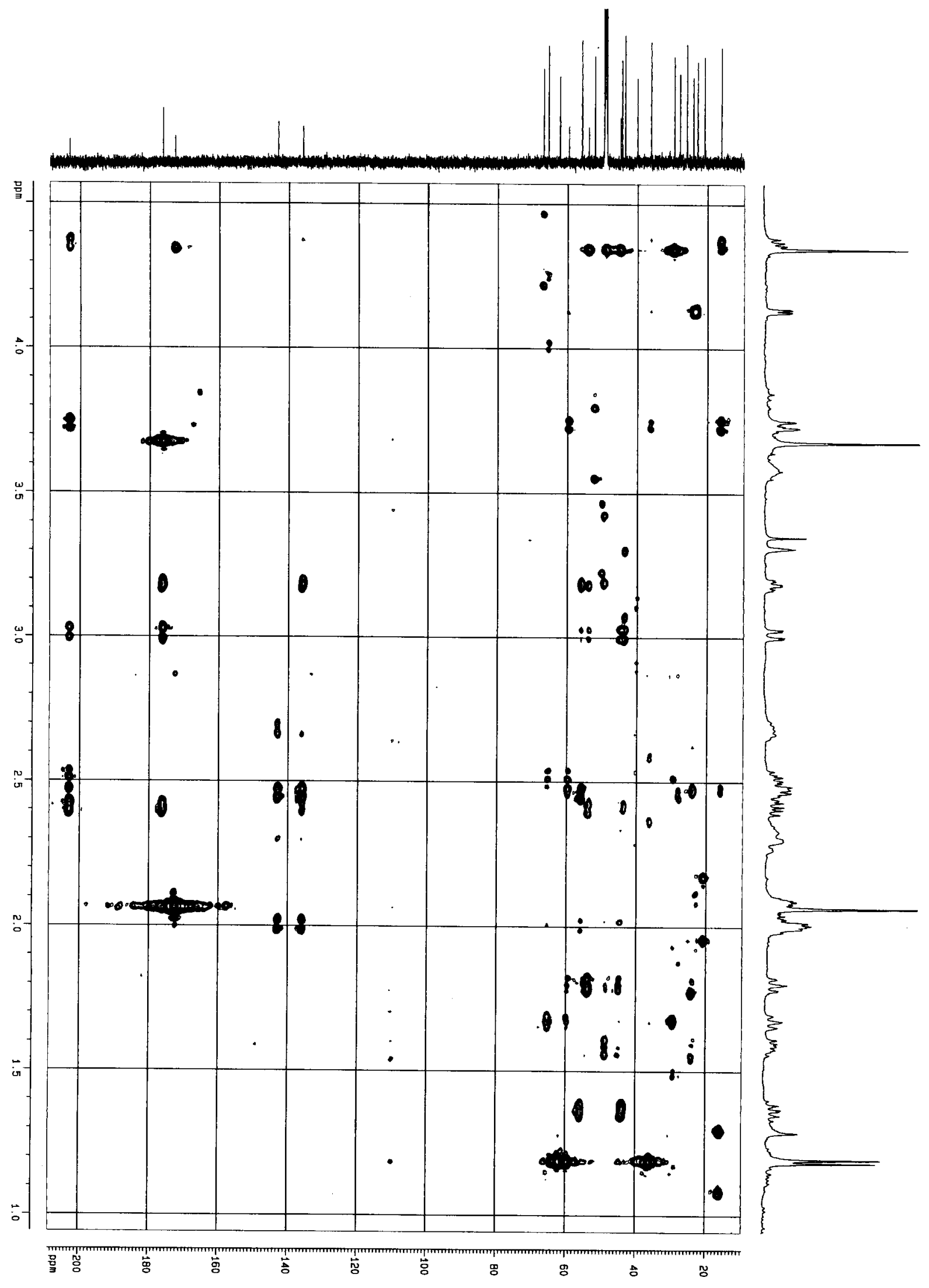

Figure S7. HMBC spectrum of daphmanidin $\mathrm{A}(\mathbf{1})$ in $\mathrm{CD}_{3} \mathrm{OD}$. 


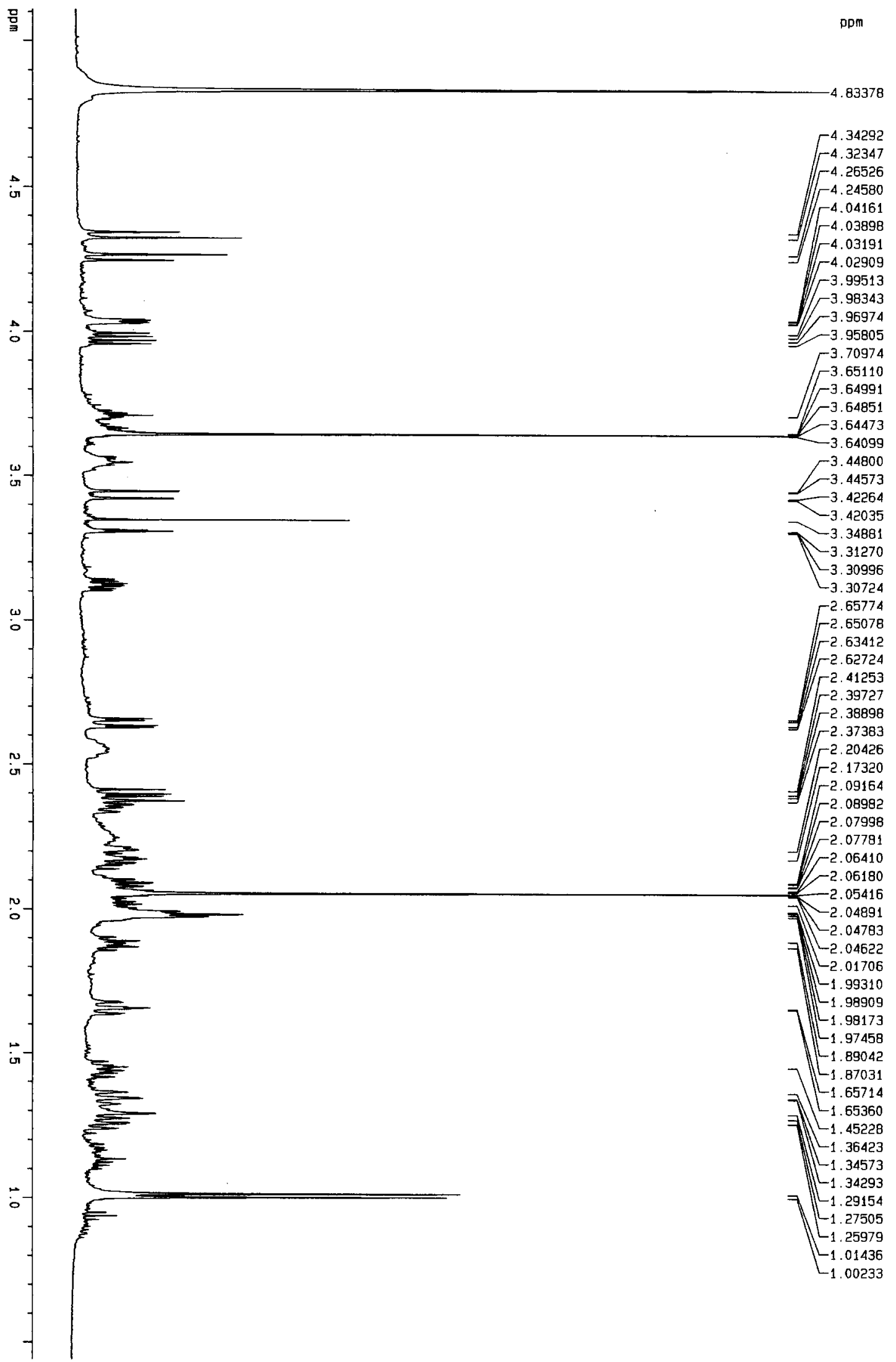

Figure S8. ${ }^{1} \mathrm{H}$ NMR spectrum of daphmanidin A (1) free base in $\mathrm{CD}_{3} \mathrm{OD}$. 


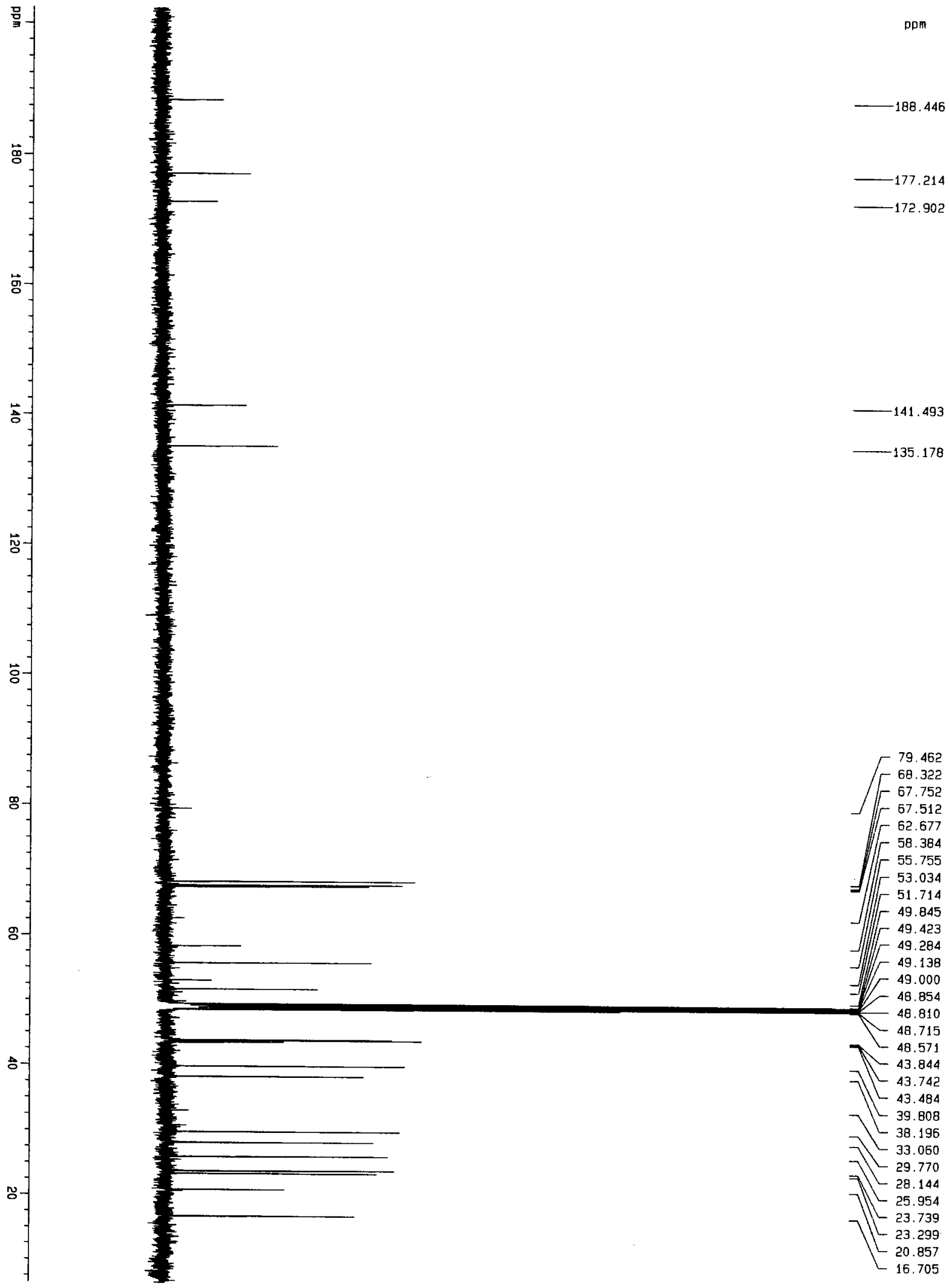

Figure S9. ${ }^{13} \mathrm{C}$ NMR spectrum of daphmanidin $\mathrm{A}(\mathbf{1})$ free base in $\mathrm{CD}_{3} \mathrm{OD}$. 


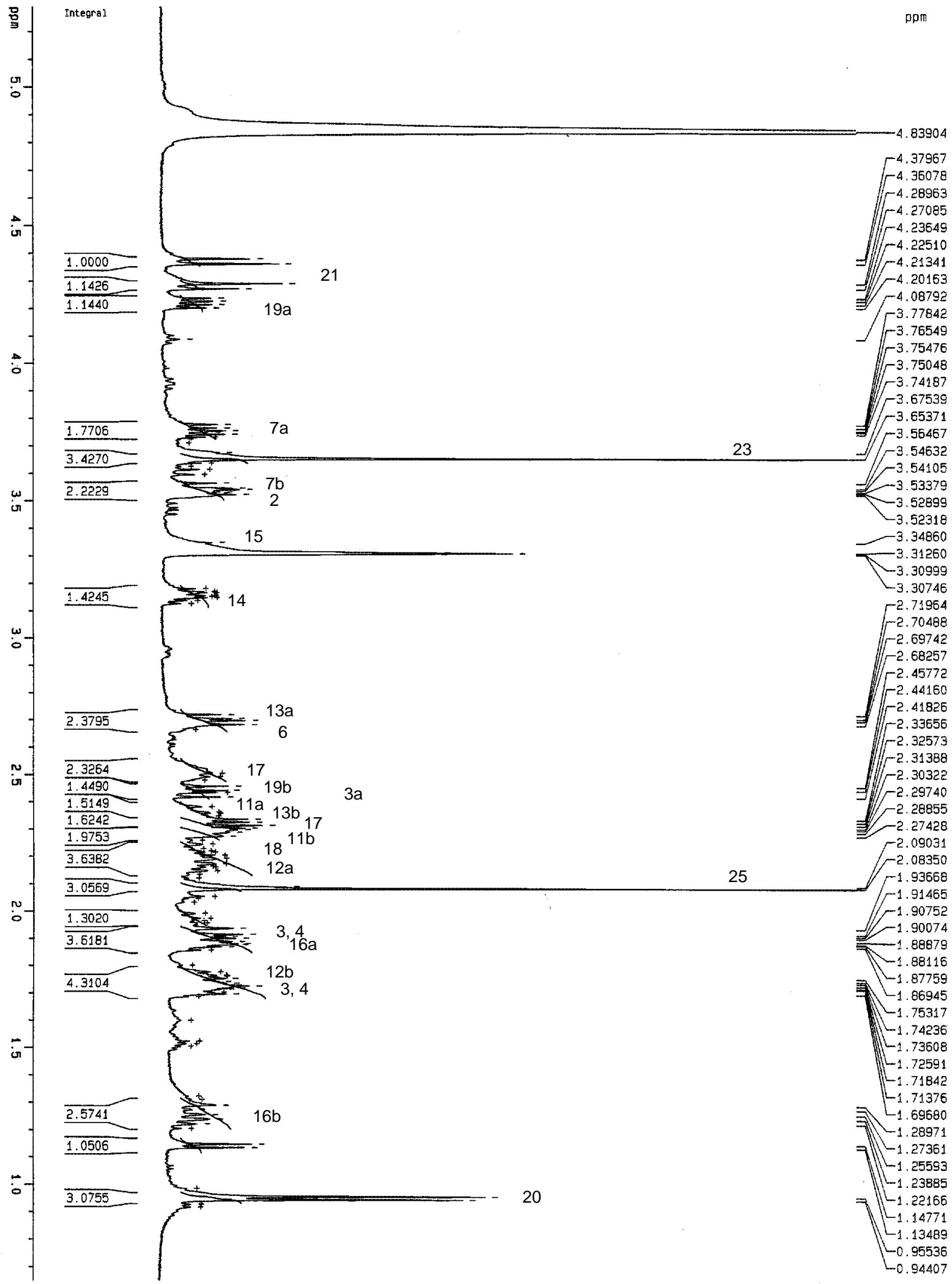

Figure S10. ${ }^{1} \mathrm{H}$ NMR spectrum of daphmanidin $\mathrm{B}(2)$ in $\mathrm{CD}_{3} \mathrm{OD}$. 


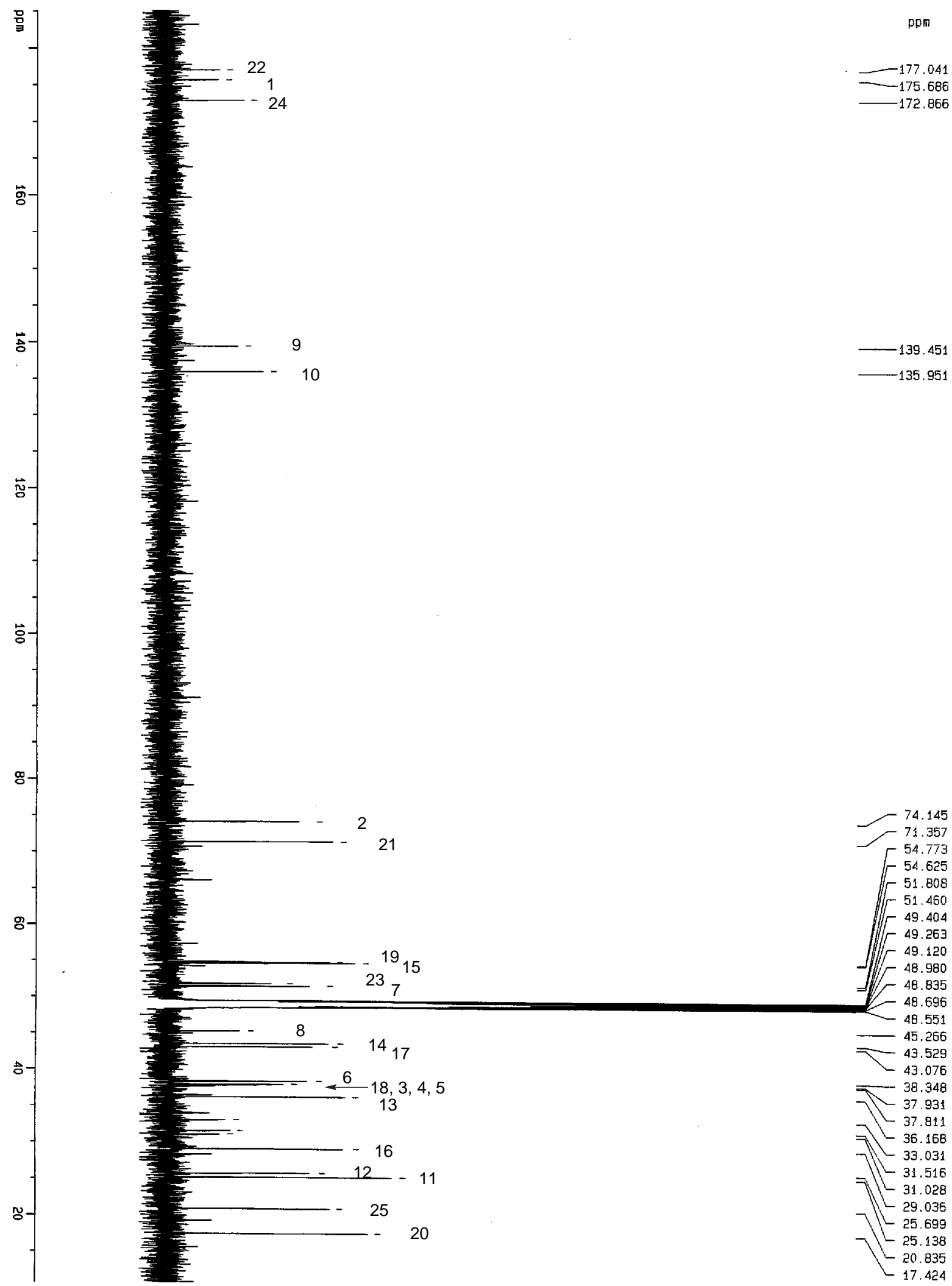

Figure $\mathrm{S} 11 .{ }^{13} \mathrm{C}$ NMR spectrum of daphmanidin $\mathrm{B}(2)$ in $\mathrm{CD}_{3} \mathrm{OD}$. 